\title{
EXPLORATORY GROUTING OF A SUBSURFACE DETENTION/INFILTRATION SYSTEM
}

\author{
Joseph A. Fischer, Joseph J. Fischer \\ Geoscience Services, 1741 Route 31, Clinton, New Jersey08809, USA, geoserv@hotmail.com
}

Todd K. Miller

400 Jefferson St., Hackettstown, New Jersey 07840, USA, millert02@centenarycollege.edu

Michael J. Miluski

Compaction Grouting Services, P.O. Box 55, Wallingford, Pennsylvania 19086, USA, mmiluski@cgsinc.net

\begin{abstract}
In 2007, a geotechnical investigation was performed for a student center at a New Jersey college. Even after reviewing the results of that study, the Municipality recommended incorporating a subsurface detention/ infiltration system below the parking lot adjacent to the student center.
\end{abstract}

The project area is underlain by solution-prone Beekmantown Formation dolomites. Mapped just to the northwest is the conformable solution-prone Allentown Dolomite. The Allentown likely dips shallowly below the Beekmantown. This local suite of carbonate bedrock lies within a fault-bounded block of these CambroOrdovician rocks.

Sinkholes formed beneath and adjacent to the basin and parking area and remediation was attempted by others. Repairs reportedly included the removal of basin fill materials, low-mobility grouting and stone backfill placed in subsurface voids. Shortly thereafter, more sinkholes opened, some within the area remediated.

Technical problems at the site included a lack of reliable subsurface information; the basin functioning in a manner that allowed infiltration; having the likely need to vary the grout and delivery procedures based upon encountered conditions and probe hole locations in relation to the basin; the need to remediate solution features trending beyond the original area of interest; and the possibility of unrecognized solution features outside the area of interest and below the student center.

These potential problems were brought to the attention of the current college administration. They quickly recognized the concerns and requested a different geotechnical firm to develop specifications for remediation and to help in choosing a suitable contractor.

To address the concerns, site-mixed grout using cement, water, mason sand and bentonite, in varying proportions, delivered under varying pressures, and using two different grout mixing methods was deemed the most appropriate remedial alternate. During the field operations, liaison and cooperation between the grouting engineers, the grout crew, and the college administration and maintenance personnel provided useful insight and support.

The various procedures used and the bases for their use are discussed in this paper. A total of 41 probe holes were drilled where a total of $157 \mathrm{~m}^{3}$ (205 cubic yards) of grout was placed. Voids as large as $5 \frac{1}{2} \mathrm{~m}$ (18 feet) in vertical extent were encountered and a maximum of $18.6 \mathrm{~m}^{3}$ (24.3 cubic yards) of grout were pumped into any single probe hole. Subsurface connection between probe holes was evidenced as grout was seen to travel at least $3 \mathrm{~m}$ (10 feet) laterally.

\section{Introduction}

A college in north-central New Jersey constructed a large, multi-purpose student center that includes a performing arts center, student cafeteria, radio station and administrative offices. The construction included a large, detention/infiltration system to handle the storm water from the structures and additional parking. The college hired a development company that had previously managed construction at the school to spearhead the new project. In the authors' opinion, after reviewing the available data, the geotechnical engineers employed for the planned construction did not seem to understand the difficulties that could result from founding such facilities atop karst terrane. 
Additionally, the municipal engineer exacerbated the problem by requiring a below-grade stormwater detention and infiltration basin under a portion of new parking area to be constructed. The basin is about 37 by $12.2 \mathrm{~m}$ ( 120 by 40 feet) in plan dimension and the bottom is about $3 \mathrm{~m}$ (10 feet) below the parking lot surface. The stormwater system consists of five rows of 1.2-meter (48-inch) diameter, perforated HDPE chambers surrounded by $19-\mathrm{mm}(3 / 4-\mathrm{inch})$ clean, washed, crushed stone with a geotextile filter placed between the existing subgrade and the system; typical construction for such systems in the northeastern U.S. The parking lot is subject to vehicle loads from passenger cars and heavy delivery trucks.

After one year of use, sinkholes formed within the parking lot and adjacent landscaped areas. Initially, crushed stone backfill was used in an effort to stabilize the sinkholes and preserve infiltration. As the sinkholes continued to grow in size and number despite repairs, the construction contractors removed approximately a third of the entire system, saving the stormwater filter structures (installed to prevent debris from compromising the system) and the HDPE chambers. Stone fill, graded rock, geogrid and geotextile (filter fabric), along with a very limited program of low-mobility grouting were used to remediate the sinkholes affecting the basin area and the system was reinstalled and the parking lot replaced.

\section{Geology}

The site lies upon a fault-bounded block of the CambroOrdovician-aged Lower Beekmantown Formation rocks (Figure 1). The Lower Beekmantown Formation is described by the New Jersey Geological Survey (NJGS) as "very thin to thick-bedded, interbedded dolomite and minor limestone. Upper beds are light-olive-gray to dark-gray, fine- to medium-grained, thin- to thick-bedded dolomite. Middle part is olive-gray-, light-brown-, or dark-yellowishorange- weathering, dark-gray, aphanitic to fine-grained, laminated to medium-bedded dolomite and light-gray to light-bluish-gray-weathering, medium-dark- to darkgray, fine-grained, thin- to medium-bedded limestone. The limestone beds grade laterally and down section into medium- gray, fine-grained dolomite. Lower beds consist of medium-light- to dark-gray, aphanitic to coarse-grained, laminated to medium-bedded, locally slightly fetid dolomite having thin black chert beds, quartz-sand laminae, and oolites. Lenses of light-gray, very coarse to coarse-grained dolomite and floating quartz sand grains and quartz-sand

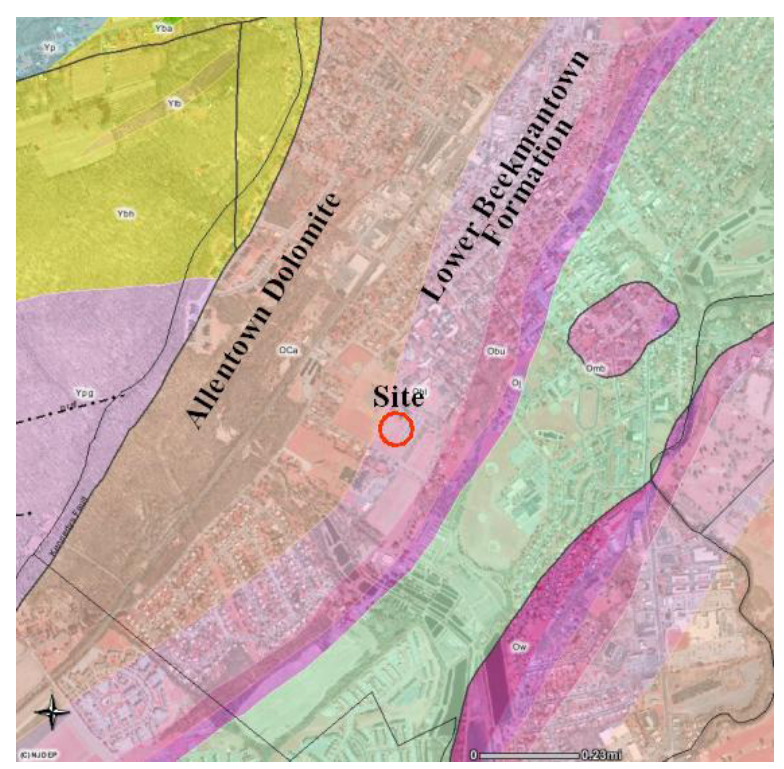

Figure 1. Bedrock geology map.

stringers at base of sequence. Lower contact placed at top of distinctive medium-gray quartzite. Unit is about $183 \mathrm{~m}$ (600 ft) thick." (NJGS, 2000).

The quality of the NJGS work in many areas of the State, with its many variations in structure, material types and tectonic history is of great value to geotechnical consultants. In this instance, comparing good test boring data to the various NJGS descriptions of the Lower Beekmantown Formation and Allentown Dolomite would have allowed a better understanding of the site subsurface.

The basin site is mapped as being very close to a formational contact with the Allentown Dolomite, which likely dips below the site at a relatively shallow depth.

In our experience, the Lower Beekmantown and Allentown have proven solution-prone wherever encountered in New Jersey and Pennsylvania.

The existence of nearby faulting is significant as much dissolution in this region is generally related to stress conditions and resultant fracturing. The southeasterly dip to the carbonates in the locale is also of significance as solutioning varies with differences in the bedrock constituents affecting cavity formation along fracture trends as well as bedding.

The Conclusions and Recommendation section of the 2007 geotechnical report starts by stating "Neither the borings 
nor our observations revealed any evidence of solutioning, subsidence, sinkhole or other karst topographic features that preclude site development." The senior author's review of the drilling logs indicate that of the 20 borings drilled deeper than $2.4 \mathrm{~m}$ ( 8 feet) below grade, 18 showed some evidence of karst features such as drilling fluid losses, soft soils atop the bedrock surface, variations in rock depth over short horizontal distances, open fractures and seams, and the redirection of the drill string from pinnacles.

\section{Stormwater Detention/Infiltration}

Subsurface infiltration of storm water after some form of sediment removal is generally considered mandatory (with some exceptions) in New Jersey. Originally, the design proposed a surface detention basin, presumably with sufficient infiltration to recharge the local groundwater regime with an equivalent amount of precipitation that would be lost to impermeable cover (a New Jersey Department of Environmental Protection [NJDEP] requirement for new construction). During the municipal review process, the Planning Board advised the college that subsurface stormwater detention/ infiltration was more desirable. In fact, the geotechnical consultant's report provided two short paragraphs of recommendations for a "subsurface stormwater disposal system" without noting any concerns for the carbonate bedrock below the basin area.

In addition, the new construction included several openbottomed stormwater inlet/dry well basins. Other such basins had been installed throughout the campus during earlier construction; their age evident by their brick and mortar construction.

So essentially, the college went ahead with the various engineering recommendations without any warning from their professionals as to the problems that could exist as a result of the karstic subsurface.

\section{Sinkhole Occurrence and Remediations}

Depressions and two sinkholes began to form in and near the parking lot surface in the fall of 2010 (Figure 2 ). The first step proposed to the college by the original consultants/designers was to video the length of the five rows of HDPE chambers. The video survey reported pipe/chamber conditions ranging from "good condition" to "punctured" and "cracked". The next step was to excavate the northwestern corner of the system. After inspecting the excavated area, one of the solutions offered

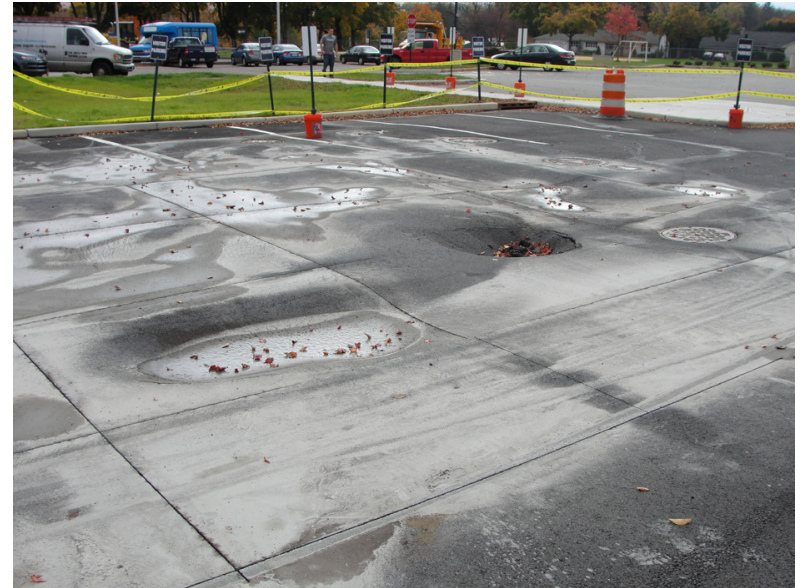

Figure 2. Sinkholes in the subsurface stormwater system.

by the original geotechnical engineering firm was to fill the sinkholes with a "cementious/fly ash flowable fill or lean concrete". In the authors experience, conventional "flowable fill" does not flow well, usually does not have sufficient cement to bond the aggregate, and shrinkage results in passages that allow water inflow and erosion into open subsurface cavities/fractures

An additional recommendation was to fill sinkhole throats with a "graded rock porous plug". This alternate would essentially construct a Class V injection well, which requires prior approval from the NJDEP, which has not been granted in any such proposal to our knowledge.

As a result of exfiltration from the system, the geotechnical consultant and general contractor recommended that the areas of concern be excavated for exploration under their technical supervision, resulting in a hole some $15.2 \mathrm{~m}$ (50 feet) wide by $18 \mathrm{~m}$ (59 feet) long by $4 \mathrm{~m}$ (13 feet) deep (Figures 3 and 4).

Before the next phase of the remediation was initiated, two more sinkholes opened. A combination of graded rock backfill (with "geogrid reinforcing") and low mobility (compaction) grouting by a specialty contractor was attempted to complete the remediation of four areas of concern (Figure 2). A total of six grout holes were planned and ten were actually drilled. The total amount of grout placed was $171 / 2 \mathrm{~m}^{3}$ (223/4 cubic yards), injected in $0.6-\mathrm{m}$ (2-foot) grouting stages until the surface was reached. A specified "volume cutoff" of $3 / 4 \mathrm{~m}^{3}$ ( 1 cubic yard) was reached in 16 of the $0.6 \mathrm{~m}$ (2-foot) stages in the ten grout holes drilled. Hence, there was no proof 
that a total of $9.75 \mathrm{~m}$ (32 feet) in these ten holes were fully grouted. This work was completed in December of 2010.

The authors were contacted in the fall of 2011 when additional sinkholes started to form in the parking lot adjacent to the stormwater system area (Figures 5 and 6). After discussions with the client and reviewing the available data for the stormwater system (which included a report from college maintenance personnel that the subsurface stormwater system had never "detained" water, even subsequent to large precipitation events), a Request for Proposal was prepared and sent to three prospective bidders, including the grouting contractor that performed the original low-mobility remediation (who declined to bid).

The other two contractors contacted provided closely competitive proposals, but previous history and the

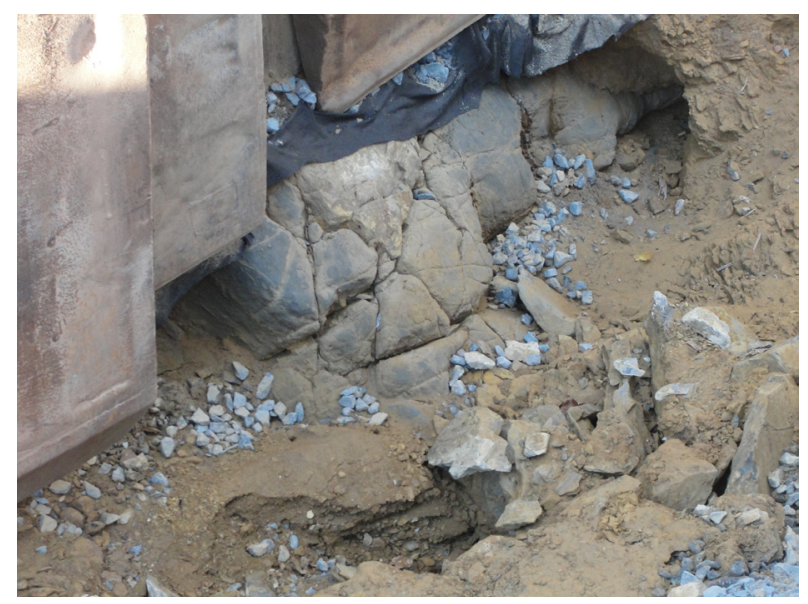

Figure 3. Exposed rock and sinkhole throat at bottom of stormwater system.

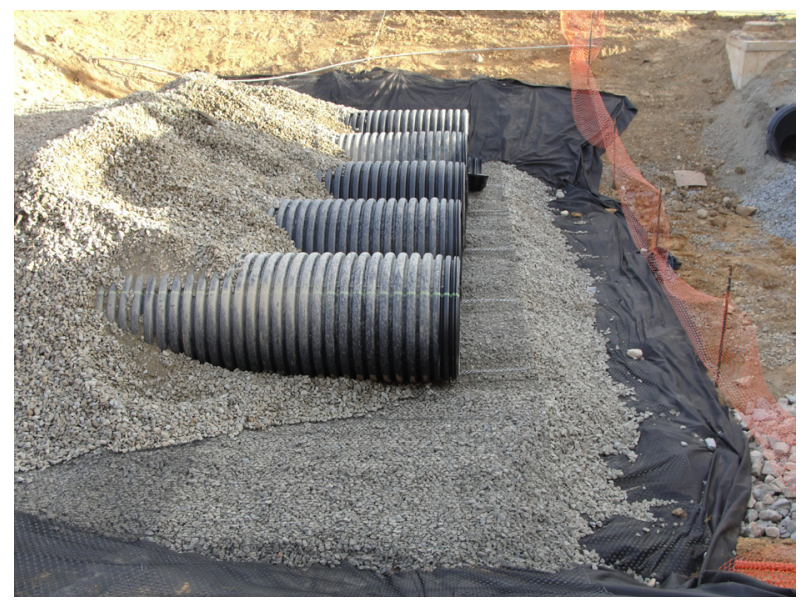

Figure 4. Reinstallation of stormwater system (note graded rock in sinkhole at bottom right of photo). ability to mix on site were important in selecting the winning bidder, Compaction Grouting Services (CGS).

\section{Grouting Concepts}

In consideration of the potential problems extant at the site, it was deemed necessary to have a flexible investigation and remediation program (e.g., Fischer and Fischer, 1995). The bid specifications included provision

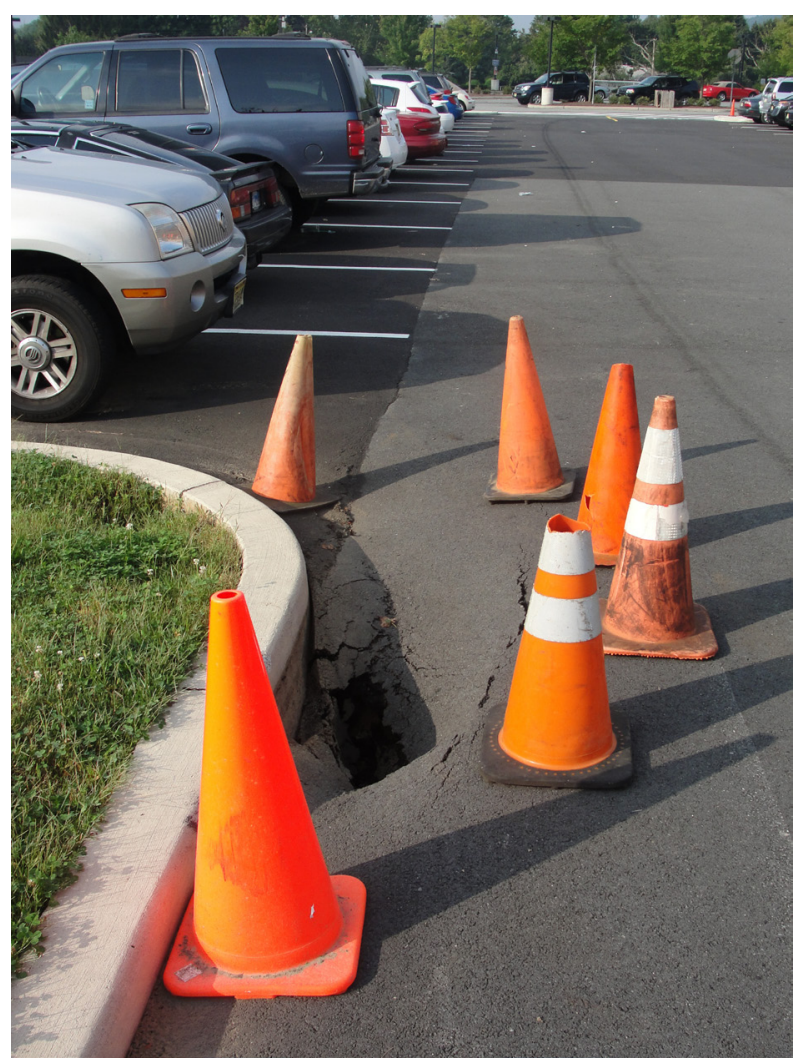

Figure 5. Parking lot sinkhole adjacent to stormwater system.

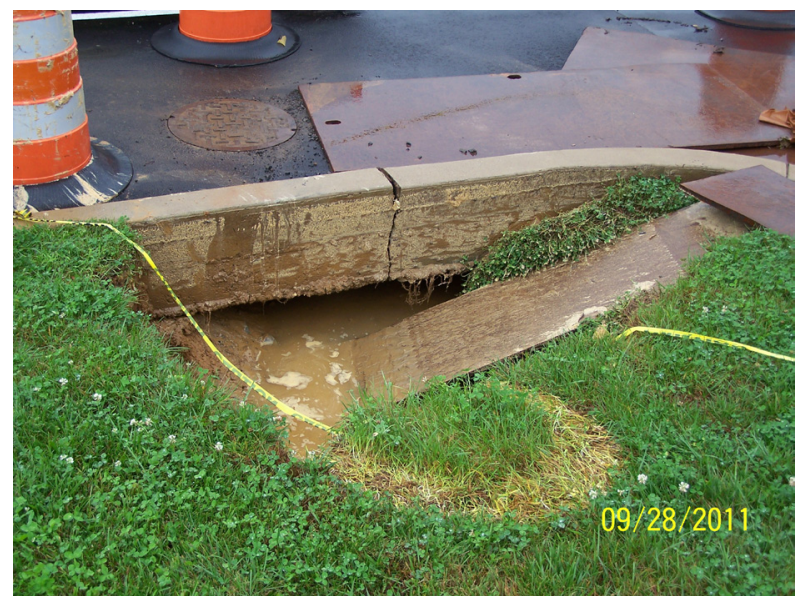

Figure 6. Parking lot sinkhole adjacent to stormwater system. 
for both high- and low-mobility grouting operations using varying proportion of cement, water, fine (e.g., mason) sand and an anti-shrinkage/fluidizer agent (in this case bentonite). Grout was to be injected through vertical and angled exploratory probes (so as to reach areas below the system without compromising the existing system) that would be logged by experienced geotechnical personnel. Alternative drilling methods were invited in the specifications and costs provided by the bidders. For economy and expediency, the grout holes were advanced using air-percussion (hydro-track) equipment.

The remediation was to be performed by a firm experienced in karst grouting. Mixers and pumps had to be able to handle a range of expected grout blends and viscosities, including the provision for a setting agent, which could change from location to location and depth upon the judgment of the grouting technician in charge. Potential ground heave was closely monitored during the grouting operations.

The need to maintain effective infiltration, as well as the variety of conditions expected during drilling within and immediately adjacent to the system required a flexible drilling and grouting program. The lack of useful and reliable subsurface information increased the original concerns for performing a quality job. To exacerbate our geotechnical concerns, the first exploratory probe hole drilled encountered an 5.5-m (18-foot) open cavity in the parking area. That hole was less than $3 \mathrm{~m}$ (10 feet) from the system and was initially drilled to isolate the stormwater system for remediation.

\section{Grouting Operations}

The stabilization program began near the subsidence features by drilling and grouting about $3 \mathrm{~m}$ (10 feet) from the detention/infiltration system, working outward from the aforementioned system. These holes were either tremie grouted or grouted under low pressure $(69-138 \mathrm{kPa}$ or $10-$ 20 pounds per square inch [psi]). The grouting began using high mobility grout produced and injected through tremie method using a ChemGrout ${ }^{\circledR}$ (CG 600 3X8DH, Figure 7) in an attempt to seal off small passages leading to the system. This system used a colloidal mixer, agitation tank and a high pressure piston pump. However, high grout takes were experienced, indicating that bedrock cavities/openings were more extensive than originally anticipated; so a lowto mid-mobility (low-mobility grouting methods using a thinner, 15- to 20-cm [6- to 8-inch] slump grout mix) grout was used except at select locations where drilling air losses were minimal and the grout holes were greater than $3 \mathrm{~m}$ (10 feet) from the system. The mid- to low-mobility grout was mixed and delivered by a $7.6 \mathrm{~m}^{3}$ (10 cubic yards) capacity mobile site mixer and a Putzmeister TK 15 HP grout/ cement pump (Figures 8 and 9).

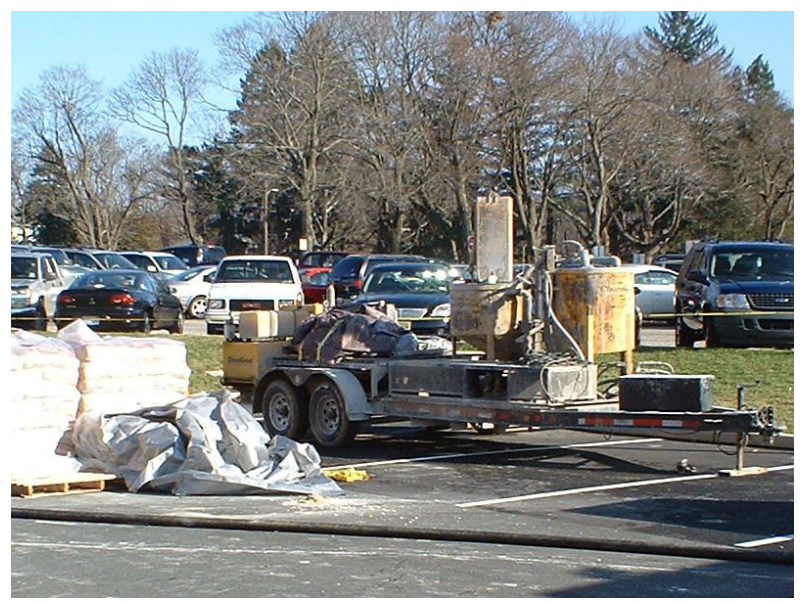

Figure 7. Chem Grout $^{\circledR}$ CG $6003 \times 8 D H$.

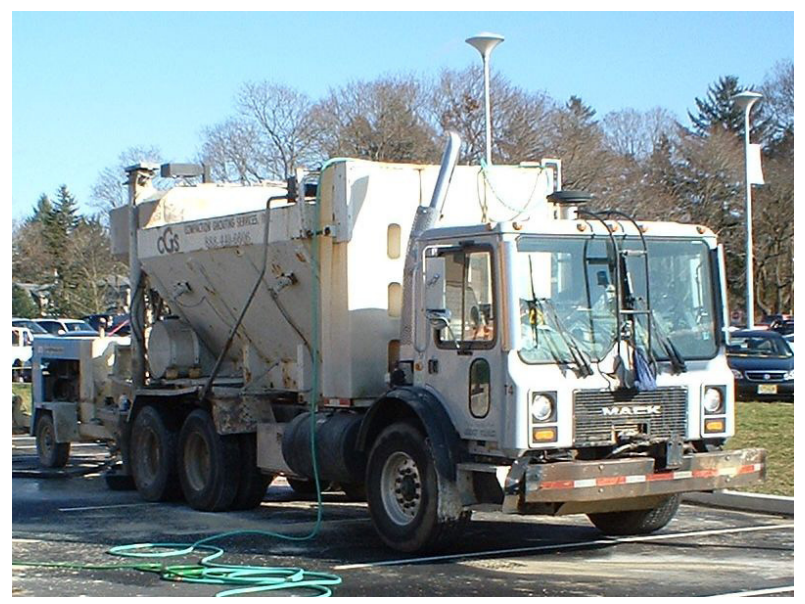

Figure 8. 10 cubic yard mobile site mixer with Putzmeister TK 15 HP pump at rear.

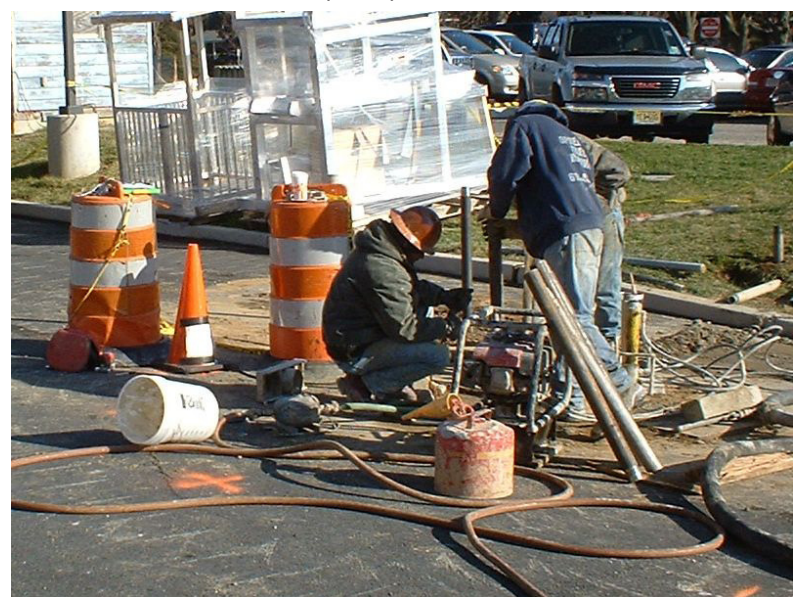

Figure 9. Installing casing into the grout hole. 
The specifications indicated that $1.5 \mathrm{~m}$ (5 feet) of sound rock was to be penetrated prior to terminating drilling. Grout injection points were drilled to depths ranging from 5.5 to $19.2 \mathrm{~m}$ (18 to 63 feet) with an average drilled depth of $8.7 \mathrm{~m}$ (28.5 feet). Some difficulties were encountered installing the grout pipe to the bottom of the drilled hole due to ledges of rock and poor quality rock. Grout takes for the injection locations ranged from about 0.02 to $2 \mathrm{~m}^{3} / \mathrm{m}$ ( 1 to 100 cubic feet per linear foot) of hole injected with an average grout take of $2.13 \mathrm{~m}^{3} / \mathrm{m}$ (23 cubic feet/linear foot) injected.

The original intent of the exploratory/grouting program was to seal the causal "throats" of the new sinkholes adjacent to or at the edge of the stormwater system to isolate it from potential areas of concern. As the work progressed (in heavy rains), a lengthy crack appeared to open in the central portion of the previously repaired system and parking lot requiring a revision to the planned program.

One unexpected problem with the grouting operations did arise as a result of the unusual subsurface conditions. While mid-mobility grouting one hole some $6 \mathrm{~m}$ (20 feet) outside the system at the $9.75-\mathrm{m}$ (32-foot) depth stage, grout did find its way into the chamber system at a compromised pipe joint. Pumping pressures (measured at the grout hole head) were just $138 \mathrm{kPa}$ (20 psi) at the time. This necessitated the removal of the grout from the system by a bucket brigade manning 19-liter (5-gallon) pails and likely helped stabilize a small section of the system with connection to a bedrock cavity.

At the location of the aforementioned crack that appeared during initial grouting operations, the centerline between the two closest, linear chamber runs of the system was "marked out". An attempt was then made to penetrate the stone fill around the system using a skid-steer mounted air-track that uses drill casing with a bit that can be extracted through the installed casing. The idea was to grout below the stormwater system, using low-mobility methods, to the bottom of the system; then removing the remaining casing while pouring pea gravel into the casing to fill the void in the system's gravel. However, the air-losses within the stone fill prevented any cuttings from reaching the surface and that drilling effort was abandoned before the bottom of the basin was reached.

\section{Site Subsurface Conditions}

As should be expected in any grouting operation, particularly at a karst site, the authors' knowledge of the subsurface was refined as more data was derived from the drilling and grouting operations. The exploratory drilling operations and subsequent grout injections revealed at least one northwest/southeast trending solution feature, likely controlled by fracturing roughly perpendicular to the general geologic strike of the region. Another solution feature seemed to parallel one edge (long axis) of the system. Although no linear pattern of sinkhole formation was evident by reconnaissance, these features became evident through exploratory drilling by cavities at varying depths and a generally deeper bedrock surface, as well as significant grout takes.

The most problematic of these solution features trended through a corner of the system and into the area of the student center, in line with one of the borings performed prior to construction where concerns were noted during the data review. This feature was followed well outside the stormwater system in an effort to preclude further collapse in the parking lot and loading ramp areas.

One other aforementioned feature appeared to be below the system, parallel to its long axis. This feature was grouted using angle holes drilled from outside the system at about a 10 degree angle so as to penetrate below the basin without encountering it directly. A mid- to lowmobility grout was then placed only to the depth of the bottom of the system.

During the operations, two solution features indicated by drilling and grouting intersected near the northeasterly corner of the system where the largest grout takes were experienced. This area evidenced extensive grout hole connection, mostly through drilling air exiting another nearby hole. On one occasion, this cross-connection evidenced drilling air connection through two probe holes bypassing another almost directly in the middle. Grout hole connections indicated by grout movement was noted, but was far less prevalent than the drilling air connection.

Another feature appeared to be related to a stormwater inlet and pipe some $12.2 \mathrm{~m}$ (40 feet) from the system and $22.9 \mathrm{~m}$ (75 feet) from the closest area of concern. Minor subsidence was noted adjacent to the inlet. This area was grouted through two holes bracketing the basin 
using high-mobility grout as extensive cavities were not encountered. Some $3.4 \mathrm{~m}^{3}$ (41/2 cubic yards) was placed in one grout hole, which then appeared within the other.

\section{Summary and Conclusions}

New Jersey regulations and space concerns are making subsurface stormwater detention/infiltration systems (with some form of preliminary treatment) more common in non-karst regions. However, as with aboveground stormwater detention, karst concerns have been accepted by some Municipal and State regulatory groups as a sound reason to completely eliminate the infiltration portion of the system. Thus, impermeable liners and qualified inspection of the subgrade by karst-experienced personnel have been more commonly recommended at sites underlain by carbonate bedrock.

As a result of the sinkhole problems in the stormwater detention/infiltration system, the stormwater inlet/dry well basins installed during previous construction were being eliminated by sealing the bottoms with concrete.

The exploration and remediation work for this subsurface stormwater detention/infiltration system was a most challenging project. It required a combined effort by a number of groups and individuals that has apparently yielded a functioning system at a difficult karst site. College administrative and maintenance personnel provided information and assistance that greatly increased the efficiency and effectiveness of the drilling and grouting operations. The flexible exploratory grouting program directed by experienced geotechnical personnel was implemented through a competent and cooperative grouting contractor and experienced crew.

The various combinations of vertical and angled drilling seemed successful and the contractor's ability to vary the grout mix upon short notice was invaluable considering the highly variable conditions below the site. Additionally, the system appears to detain water after precipitation events as a result of the remediations described herein, yet still effectively allows infiltration.

As with most grouting projects, these operations were deemed complete without full knowledge of the extent of solutioning in the area of concern and the ability of any grouting concept to eliminate all future problems. However, to date, no evidence of additional problems have revealed themselves in the vicinity of the subsurface detention/infiltration basin.

More than $245 \mathrm{~m}$ (800 feet) away, however, a sinkhole appeared at a combination catch basin and dry well located in an older portion of the campus underlain by the Allentown Dolomite. As important infrastructure was not threatened, a simple fix was employed; excavate in an effort to find the throat, inspection, flooding and the introduction of a "pumpable flowable fill" mix.

\section{References}

Fischer JA, Fischer JJ. 1995. Karst site remediation grouting. In: Beck, BF, editor. Karst Geohazards, Engineering and Environmental Problems in Karst Terrane. Proceedings of the Fifth Multidisciplinary Conference on Sinkholes and the Engineering and Environmental Impacts of Karst; 1995 April 2-5; Gatlinburg, Tennessee. Rotterdam (Netherlands): A.A. Balkema. p. 325-330.

New Jersey Geological Survey. 2000. Bedrock geology and topographic base maps of New Jersey, NLEGEND.pdf. In New Jersey Geological Survey CD Series CD 00-1. 
